IZA DP No. 6361

Educational Segregation and the Gender Wage Gap for Recent College Graduates in Colombia

Laura Cepeda Emiliani

Juan D. Barón

February 2012

Forschungsinstitut zur Zukunft der Arbeit Institute for the Study of Labor 


\title{
Educational Segregation and the Gender Wage Gap for Recent College Graduates in Colombia
}

\author{
Laura Cepeda Emiliani \\ Central Bank of Colombia \\ Juan D. Barón \\ Central Bank of Colombia \\ and IZA
}

\section{Discussion Paper No. 6361 \\ February 2012}

IZA
P.O. Box 7240
53072 Bonn
Germany

\author{
Phone: +49-228-3894-0 \\ Fax: +49-228-3894-180 \\ E-mail: iza@iza.org
}

\begin{abstract}
Any opinions expressed here are those of the author(s) and not those of IZA. Research published in this series may include views on policy, but the institute itself takes no institutional policy positions.

The Institute for the Study of Labor (IZA) in Bonn is a local and virtual international research center and a place of communication between science, politics and business. IZA is an independent nonprofit organization supported by Deutsche Post Foundation. The center is associated with the University of Bonn and offers a stimulating research environment through its international network, workshops and conferences, data service, project support, research visits and doctoral program. IZA engages in (i) original and internationally competitive research in all fields of labor economics, (ii) development of policy concepts, and (iii) dissemination of research results and concepts to the interested public.
\end{abstract}

IZA Discussion Papers often represent preliminary work and are circulated to encourage discussion. Citation of such a paper should account for its provisional character. A revised version may be available directly from the author. 


\section{ABSTRACT}

\section{Educational Segregation and the Gender Wage Gap for Recent College Graduates in Colombia}

In this paper we show the importance of subject of degree in explaining the gender wage gap in Colombia. In order to minimize the influence of gender differences in experience, promotions, and job changes on the wage gap, we focus on college graduates who have a formal job and who have been in the labor market at most one year. Using unique, administrative datasets with detailed subjects of degree, we find that the wage gap against women is on average $11 \%$ and that $40 \%$ of it can be explained by differences in subject of degree. Using a distributional decomposition, we find an increasing gender wage gap across the distribution of wages (from $2 \%$ at the bottom to $15 \%$ at the top), although subject of degree explains a lower 30\% of the gap at the top. Policies designed to reduce the gender wage gap need to address the differing gender educational choices and the factors that influence them. These policies would be more effective in reducing the gap for median wage earners.

JEL Classification: J24, J31, J71

Keywords: gender wage gap, subject of degree, decomposition

Corresponding author:

Laura Cepeda Emiliani

Calle 33 No. 3-123

Centro

Cartagena de Indias

Colombia

E-mail: Icepedem@banrep.gov.co

\footnotetext{
* This article uses microdata from the Colombian Graduates Database, which is administered by the Labor Observatory of the Ministry of Education. The findings and views in this article are the authors' and should not be attributed to the Ministry of Education, the Banco de la República (Central Bank of Colombia) or its Board of Directors. The authors would like to thank Mathias Sinning, Deborah CobbClark, Eva Vivalt, Claudia Ruiz Ortega, Javier Pérez, Adolfo Meisel, Lina Cardona, Rodrigo Taborda, Ximena Peña, Aakankshka Pande, Julio Romero and Eliana Carranza for helpful comments.
} 


\section{Introduction}

According to the Global Gender Gap Report 2011, Colombia is a country where women face higher gender differences in pay. In the sample of 135 countries, the country ranks 94 in the index of wage equality for similar work (Hausmann et al., 2011). Moreover, information from labor surveys indicate that women earn on average $13.5 \%$ lower wages than men.

Given this panorama and the fact that differences in pay do not necessarily imply discrimination in the labor market (but gender differences in characteristics), it is important to understand what really drives the gender wage gap. Economists decompose the gender wage gap into two parts, one explained by standard personal and job characteristics found in survey data (such as age, experience, educational level, and industry), and another one that remains unexplained (reflecting gender differences in unobserved traits and returns to characteristics). In Colombia, most of the gender wage gap cannot be explained by gender differences in observable characteristics (Hoyos et al., 2007).

In this paper we investigate the importance of subject of degree in explaining the gender wage gap in Colombia, by taking advantage of unique, administrative datasets for two cohorts of college graduates. Our working dataset combines education data from the Ministry of Education and wage data from social security records from other ministries. The nature of the datasets (big sample and detailed subject of degree not available in surveys) allows us to precisely estimate the relationship between gender wage gaps and the differing educational choices of men and women. In order to minimize the influence of gender differences in experience, promotions, and job changes on the wage gap, we focus on college graduates who have a formal job and who have been in the labor market at most one year ${ }^{1}$ In that way, we shed some light on the gender wage differences that workers joining the formal labor market face.

Specifically, we are interested in i) whether the wage gap exists during the first year of labor market experience after college graduation, but more importantly, on ii) whether differing choices of subject of degree between men and women contribute to explain the average gender

\footnotetext{
${ }^{1}$ There is no gender difference in the probability of having a formal job for this population of highly educated workers. Roughly $80 \%$ of graduates are employed during the first year of graduating from college.
} 
wage gap for recent graduates, and iii) the extent to which subject of degree is relevant in explaining the wage gap at different levels of the wage distribution (thus, helping to explain phenomena such as sticky floors or glass ceilings).

A recent branch of the literature analyzes gender differences in pay for individuals with higher qualifications, college graduates, and finds that subject of degree matters: it increases the explained part of the gap by almost 20 percentage points (or 43\%) in the UK, and from 26 to 35 percentage points (or 31\%) in Germany, when included with standard wage gap predictors such as industry and region (Machin and Puhani, 2003). Lin (2010) finds similar results for Taiwan. These studies focus on all graduates without regard of how long they have been in the labor market and, therefore, incorporate many labor market dynamics that could influence the gender wage gap and that are difficult to control for.

Our work relates more closely to McDonald and Thornton (2007), who use the annual surveys of the National Association of Colleges and Employers (NACE) to analyze starting salary offers for new college graduates and find that as much as $95 \%$ of the gender wage gap in starting salary offers can be explained by college major. In the same vein, our work also relates to Chevalier (2007) who analyzes survey data to find that subject of degree explains almost a quarter of the gender wage gap for UK recent graduates, even when controlling for gender differences in personal and job characteristics, occupation, and career expectations. These two studies are based on survey data with either a small sample size or only broad subject of degree categories. Our work, additionally, analyzes not only average wage gaps in a developing country (something that to our knowledge, has not been done for recent graduates) but also across the wage distribution.

There seem to be good reasons to believe that subject of degree explains the difference in pay we observe between men and women. If supply and demand generate different wages for different college graduates, higher graduation rates of women from low-paying degrees will inevitably create a gender wage gap. For example, anecdotal evidence suggests that a higher proportion of men graduate from engineering, and that engineers receive a higher than average wage in the market, hence contributing to the existence of a pay gap between men and women. 
Although it is important to recognize that future expectations about labor market conditions influence the decision to study specific degrees (for example, if women anticipate future wage gaps or lower job flexibility linked to particular degrees), this paper takes these decisions as given.

The remainder of the paper is as follows: in the next section we discuss the data and describe gender segregation by subject of degree. In section 3, we decompose the mean gender wage gap using the standard Blinder-Oaxaca methodology, and also decompose the gender wage gap at the 10th, 50th and 90th percentiles using the distributional decomposition put forward by Firpo et al. (2009). In each of these decompositions, we use specifications with and without subject of degree. For subject of degree we use two measures, a more aggregated measure (area of study) and a more detailed measure (field of study). Section 4 concludes.

\section{Gender and Subjects of Degree of Recent College Graduates}

To construct our sample, we start with microdata from the Graduates Database, administered by the Labor Observatory for Education (OLE, by its acronym in Spanish) of the Colombian Ministry of Education. This is a unique database that includes information for every person who obtained a college degree during 2001-2009 from an institution of higher education registered with the Ministry. This information is supplied by the institutions of higher education and reported to the National System of Information for Higher Education (SNIES, by its acronym in Spanish). The database includes information for both undergraduate (and vocational) and graduate studies (specialization, master's and $\mathrm{PhD}$ ). The database also includes gender, area and field of study, graduation date, and the name of the institution of higher education. Some characteristics of the institution and program are also included, such as the type of institution (public or private), location (municipality and department) and the form of study (on-campus or distance/online education).

The uniqueness of the data comes from merging this information with wages from social security records at the individual level (Ministry of Social Protection and Ministry of Finance). The resulting database is known as the Integrated Graduate Database. This database indicates 
if the person is working and is making contributions to social security, and includes their salaries subject to social security contributions.

Our working sample consists of individuals who graduated in 2007 and 2008, and who worked in the formal sector (jobs that make contributions to social security, particularly health and pension) in the year after their graduation, 2008 and 2009, respectively, with only one undergraduate degree, and no previous higher studies. Individuals who obtained degrees through distance education were not taken into account as their age profile might differ. Also excluded were those with a vocational degree, as opposed to an academic one. There are 99,704 graduates that meet these criteria, and thus constitute our working sample. The sample is restricted this way to observe individuals during their first year on the job market, that is, when they just graduated and have limited or no work experience, so we have a more homogeneous group both in terms of experience and age (this dataset does not provide age or experience) $\mathrm{U}^{2}$ This dataset provides unique information, not available from other sources, on subject of degree and wages for nearly all university graduates in Colombia.

Table 1 shows the gender distribution by area of study (our eight-category aggregate measure of subject of degree), the average monthly wages, and the female-to-male wage ratio. The more disaggregated categorization of subject of degree used in the following section, field of study, consists of 51 categories (see Table A1 in the appendix) 3 $^{3}$ There are marked gender differences in area of study in Colombia. The evidence in the table reveals that women are heavily underrepresented in high-paying areas such as engineering, and overrepresented in the low-paid education sciences. Even when women are overrepresented in high-paying jobs (economics, business and accounting), they tend to earn less than men (only $87 \%$ of men's wage). Moreover, in all areas, except in liberal arts, average earnings of women are between 87 and $94 \%$ of men's. The problem with this broad categorization is that it hides large variations in

\footnotetext{
${ }^{2}$ The dataset only provides information for labor income received on a monthly basis, but not the hours worked during that period. However, information from the 2007 and 2008 household surveys indicates that employed graduates, aged 21 to 24 years old, report working on average 44.8 hours per week, with women working slightly less than one hour than men. We also carry out the analysis excluding the bottom $10 \%$ of the wage distribution for men and women separately, in an attempt to exclude people who work less than full time. The results are qualitatively similar to the ones presented.

${ }^{3}$ The Ministry of Education reports 55 categories for field of degree. We exclude four categories, which do not have enough observations, from the analysis.
} 


\section{Table 1: Subject of Degree (Area of Study) and Gender Wage Gaps ${ }^{(a)}$}

\begin{tabular}{|c|c|c|c|c|}
\hline Subject & $\begin{array}{c}(1) \\
\text { Female } \\
\text { graduates, \% }\end{array}$ & $\begin{array}{c}(2) \\
\text { Male } \\
\text { graduates, \% }\end{array}$ & $\begin{array}{c}(3) \\
\text { Average montly } \\
\text { wage ('000) }\end{array}$ & $\begin{array}{c}(4) \\
\text { Wage ratio } \\
\left(w^{f} / w^{m}\right)\end{array}$ \\
\hline Agronomy and veterinary sciences & 0.8 & 1.7 & 1,068 & 0.89 \\
\hline Liberal Arts & 2.9 & 3.0 & 1,224 & 1.01 \\
\hline Education Sciences & 12.4 & 7.5 & 927 & 0.91 \\
\hline Health Sciences & 15.4 & 8.7 & 1,568 & 0.88 \\
\hline Social Sciences and Humanities & 18.3 & 13.2 & 1,389 & 0.90 \\
\hline Economics, Business, and Accounting & 29.2 & 21.8 & 1,350 & 0.87 \\
\hline Engineering, Architecture, and Urbanism & 18.7 & 41.8 & 1,498 & 0.92 \\
\hline Mathematics and Natural Sciences & 2.3 & 2.5 & 1,414 & 0.94 \\
\hline Total & 100.0 & 100.0 & 1,377 & 0.88 \\
\hline
\end{tabular}

(a) The total sample used is 99,704 (54,505 women and 45,199 men). The sample includes only college graduates with a formal job. In column $(4), w^{(f)}$ corresponds to average female wages and $w^{(m)}$ to average male wages.

Source: Authors' calculations using social protection records and information from the Ministry of Education for 2007 and 2008 college graduates.

wage rates for degrees with large gender segregation, as for example, nurses versus medical practitioners in the Health Sciences category. To avoid this, we also use the more detailed field of study in the decompositions that follow.

\section{Decomposition}

In order to study the contribution of subject of degree to the gender wage gap, we estimate separate log wage equations for men and women. We then use the Blinder-Oaxaca methodology to decompose the mean wage gap as $\ln \bar{W}^{m}-\ln \bar{W}^{f}=\left(\bar{X}^{m}-\bar{X}^{f}\right) \beta^{m}+\bar{X}^{f}\left(\beta^{m}-\beta^{f}\right)$, where $W$ represents monthly wage, $X$ are predictors in the wage equation, and $\beta$ are the coefficients from the estimation of separate earnings functions for men $(m)$ and women $(f)$ (Blinder, 1973 , Oaxaca, 1973). The first term on the right-hand side of the equation is known as the composition effect, or "explained" component, reflecting gender differences in average $X$ values; and the second term is the wage effect, or the "unexplained" part of the gap. Although this last term includes differences that can be attributed to gender discrimination, it also contains gender differences in unobserved characteristics that might be important in explaining gender differences in pay, such as personality, risk aversion, ambition, networking and communication skills, among others.

As written, the decomposition assumes that discrimination is against women and that 
there is no positive discrimination towards men (Oaxaca, 1973). However, it is often the case that there is no reason to assume that the coefficients of one of the two groups is nondiscriminating. To verify the robustness of our results, we estimate different models, that use men coefficients (as above), women coefficients (that change men for women and, also, women for men above), and average coefficients for both to calculate the nondiscriminatory parameters as $\beta=0.5 \beta^{m}+0.5 \beta^{f}$ Reimers, 1983).

Table 2 presents the decomposition results. Under specification 1 we include controls for type of university attended (public or private), graduation semester and year, and state where the institution is located. In this specification we restrain from including any controls for area or field of study. Specification 2 includes area of study (8 categories), in addition to controls from specification 1, and specification 3 includes the detailed field of study (51 categories). This strategy allows us to measure how much subject of degree contributes to explain the wage gap.

Panel $\mathrm{A}$ in Table 2 shows that the raw gender wage gap is $10.7 \%$ against women. Despite the fact that the samples are not comparable, this wage gap is of similar magnitude as the one documented by Hoyos et al. (2007) for the general case of Colombia. It is also close to the $12.4 \%$ gender gap found for recent UK graduates (Chevalier, 2007).

Table 2 shows that our specification 1, the one with the limited set of variables we are able to control for, does not explain gender differences in pay, and simply suggests that average characteristics of these variables are slightly higher for women. Thus, the composition effect, or explained part, is small and slightly negative. The different estimates for specification 1 suggest that the use of male, female, or a weighted average of coefficients has no effect on the result. In this case the wage effect dominates the decomposition.

Including subject of degree, either by including our 8-category area of study or our 51category field of study measures, is important in explaining the observed wage gap. When we include area of study (specification 2), the composition effect, or the differences brought about by, mainly, gender differences in this variable, explains between 6.6 and $15.1 \%$ of the gender wage gap, depending upon the coefficients used to carry out the decomposition. More 
Table 2: Gender Wage Gap: Oaxaca-Blinder Decomposition $\operatorname{Results}^{(a)}$

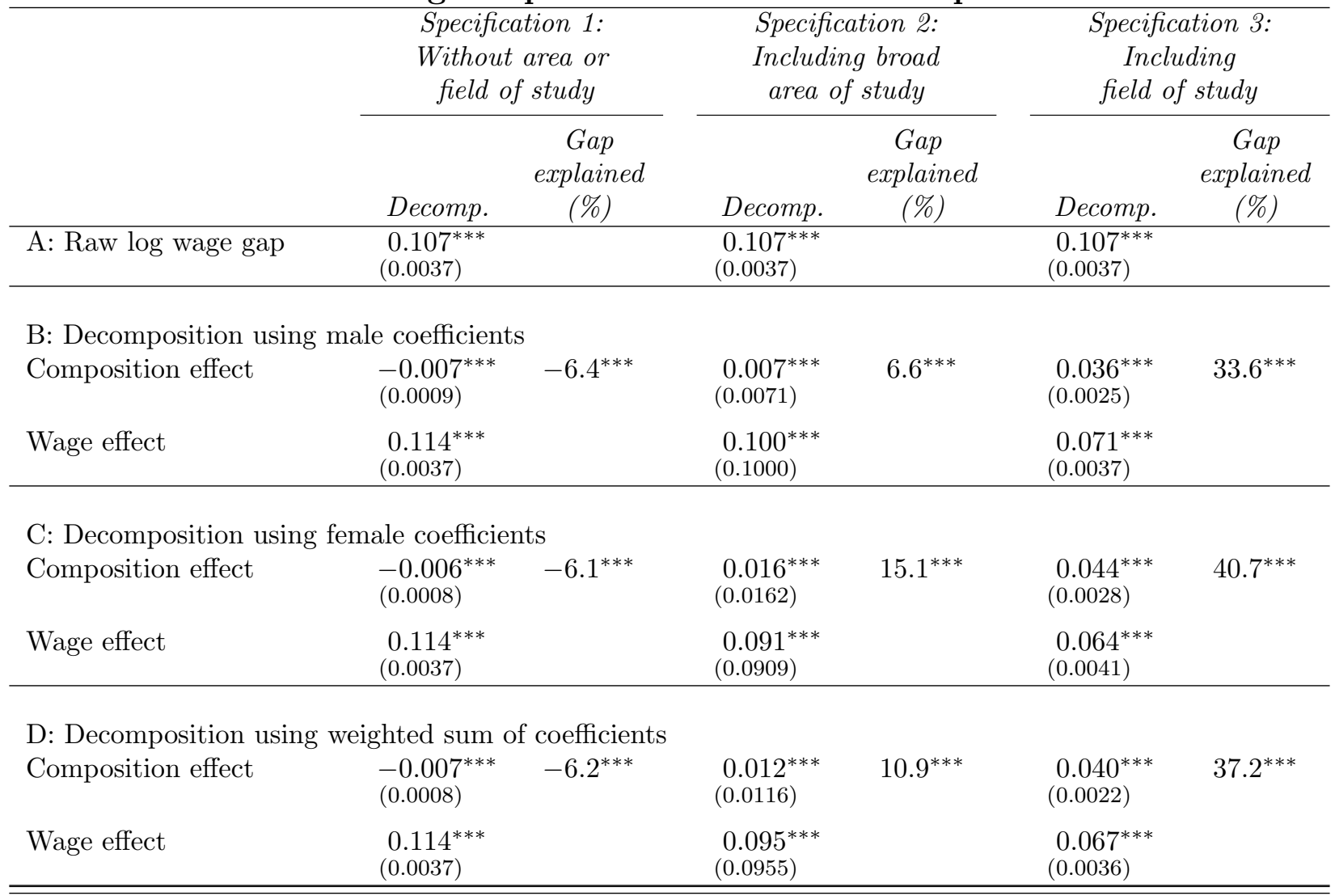

Note: (a) The sample for all decompositions is 99,704 observations (54,505 women and 45,199 men). Bootstraped standard errors in parentheses, 300 repetitions. ${ }^{(* *)}$ denotes statistical significance at the $1 \%$ level. All three specifications include controls for type of university (public or private), year dummies, semester of graduation dummies, and dummy variables for the state where the university is located. In addition to these, specification (2) includes eight areas of study, and specification (3) includes 52 fields of study. The percentage of the gap explained is calculated as the compositions effect divided by the corresponding raw log wage gap.

Source: Authors' calculations using social protection records and information from the Ministry of Education for 2007 and 2008 college graduates.

importantly, when we instead use field of study (specification 3), the composition effect increases to between $33.6 \%$ and $40.7 \%$. This implies that the educational choices in terms of subject of degree matter for the explanation of the gender wage difference we observe in the data..$^{4}$ Note that the unexplained part also captures all gender differences in variables we are unable to control for.

These results are consistent with those for the UK and Germany Chevalier, 2007; Machin and Puhani, 2003), the United States (McDonald and Thornton, 2007), and Taiwan (Lin, 2010), despite the fact that the populations under study are different.

One recurrent characteristic of the gender wage gap, documented in the literature, is

\footnotetext{
${ }^{4}$ We also carried out the matching decomposition proposed by Nopo (2008), finding similar results to the ones presented here.
} 
that in many countries the wage gap changes with the level of pay (for Europe, Arulampalam et al., 2007, for Australia, Barón and Cobb Clark, 2010; for Colombia, Hoyos et al., 2007), suggesting the existence of sticky floors or glass ceiling effects (Albrecht et al., 2003). Given this, it is interesting to analyze whether in the short period that these individuals have been out in the labor market, these phenomena are already present, and if so, how much subject of degree contributes to the gender wage gap at different points of the wage distribution.

To decompose the wage gap across the distribution, we use the decomposition proposed by Firpo et al. (2009) based on Recentered Influence Functions (RIF). These regressions are a convenient way to perform Blinder-Oaxaca type decompositions for distributional statistics different from the mean, in our case quantiles.

A RIF-regression is similar to a standard regression, with the difference that the dependent variable, $W$, is substituted by the recentered influence function of the quantile of interest. The influence function $I F\left(W, Q_{\tau}\right)$ is given by $\left[\tau-I\left\{W \leq Q_{\tau}\right\}\right]\left[f_{W}\left(Q_{\tau}\right)\right]^{-1}$ where $I\{$.$\} is an$ indicator function, $f_{W}($.$) is the density of the marginal distribution of W$, and $Q_{\tau}$ is the population $\tau$-quantile of the unconditional distribution of $W$. In this manner, the recentered influence function is given by $\operatorname{RIF}\left(W ; Q_{\tau}\right)=Q_{\tau}+\left[\tau-I\left\{W \leq Q_{\tau}\right\}\right]\left[f_{W}\left(Q_{\tau}\right)\right]^{-1}$.

To estimate the RIF, we need to compute the sample quantile $\widehat{Q}_{\tau}$ and then estimate the density at that point using traditional kernel methods (we use a gaussian kernel function and the bandwidth is chosen to minimize the mean integrated squared error). For each observation, we can estimate $\widehat{R I F}\left(W_{i} ; Q_{\tau}\right)$ by plugging the estimates $\widehat{Q}_{\tau}$ and $\widehat{f}\left(\widehat{Q}_{\tau}\right)$ into the RIF formula.

Once we calculate the RIF for each observation, and the quantile of interest, we use this new variable, $\widehat{R I F}\left(W_{i} ; Q_{\tau}\right)$, instead of $W$, to carry out a Blinder-Oaxaca decomposition. We repeat the procedure for each quantile of interest. Firpo et al. (2009) and Fortin et al. (2011) provide details of the decomposition and its properties, as well as comparisons with other decomposition methods.

Table 3 shows the results for the FFL decomposition for the same specifications as in Table 2, and for quantiles 10th, 50th (the median), and 90th. Given that Table 2 shows that results are not sensitive to the selection of coefficients used (men's or women's), all decompo- 
Table 3: Gender Wage Gap Decomposition (Weighted Sum of Coefficients): RIF Decomposition of the 10th, 50th, and 90th Percentiles. ${ }^{(a)}$

\begin{tabular}{|c|c|c|c|c|c|c|}
\hline & \multicolumn{2}{|c|}{$\begin{array}{l}\text { Specification 1: } \\
\text { Without area or } \\
\text { field of study }\end{array}$} & \multicolumn{2}{|c|}{$\begin{array}{l}\text { Specification 2: } \\
\text { Including broad } \\
\text { area of study }\end{array}$} & \multicolumn{2}{|c|}{$\begin{array}{l}\text { Specification 3: } \\
\text { Including } \\
\text { field of study }\end{array}$} \\
\hline & Decomp. & $\begin{array}{c}\text { Gap } \\
\text { explained } \\
(\%)\end{array}$ & Decomp. & $\begin{array}{c}\text { Gap } \\
\text { explained } \\
(\%)\end{array}$ & Decomp. & $\begin{array}{c}\text { Gap } \\
\text { explained } \\
(\%)\end{array}$ \\
\hline $\begin{array}{l}\text { A: Decomposition } \mathrm{f} \\
\text { Raw log wage gap }\end{array}$ & $\begin{array}{c}\text { o }^{t h} \text { percenti } \\
0.016^{* * *} \\
(0.0021)\end{array}$ & & $\begin{array}{l}0.016^{* * *} \\
(0.0021)\end{array}$ & & $\begin{array}{l}0.016^{* * *} \\
(0.0021)\end{array}$ & \\
\hline Composition effect & $\begin{array}{l}-0.002^{* * *} \\
(0.0005)\end{array}$ & $-12.5^{* * *}$ & $\begin{array}{l}0.002^{* * *} \\
(0.0008)\end{array}$ & $12.5^{* * *}$ & $\begin{array}{l}0.006^{* * *} \\
(0.0010)\end{array}$ & $37.5^{* * *}$ \\
\hline Wage effect & $\begin{array}{l}0.017^{* * *} \\
(0.0020)\end{array}$ & & $\begin{array}{l}0.013^{* * *} \\
(0.0020)\end{array}$ & & $\begin{array}{l}0.009^{* * *} \\
(0.0022)\end{array}$ & \\
\hline $\begin{array}{l}\text { B: Decomposition fo } \\
\text { Raw log wage gap }\end{array}$ & $\begin{array}{c}\text { th percenti } \\
0.118^{* * *} \\
(0.0050)\end{array}$ & & $\begin{array}{l}0.118^{* * *} \\
(0.0050)\end{array}$ & & $\begin{array}{l}0.118^{* * *} \\
(0.0050)\end{array}$ & \\
\hline Composition effect & $\begin{array}{l}-0.010^{* * *} \\
(0.0010)\end{array}$ & $-8.5^{* * *}$ & $\begin{array}{l}0.022^{* * *} \\
(0.0020)\end{array}$ & $18.6^{* * *}$ & $\begin{array}{l}0.050^{* * *} \\
(0.0027)\end{array}$ & $42.4^{* * *}$ \\
\hline Wage effect & $\begin{array}{l}0.129^{* * *} \\
(0.0049) \\
\end{array}$ & & $\begin{array}{l}0.096^{* * *} \\
(0.0050)\end{array}$ & & $\begin{array}{l}0.068^{* * *} \\
(0.0051)\end{array}$ & \\
\hline $\begin{array}{l}\text { C: Decomposition f } \\
\text { Raw log wage gap }\end{array}$ & $\begin{array}{c}\text { th percenti } \\
0.149^{* * *} \\
(0.0061)\end{array}$ & & $\begin{array}{l}0.149^{* * *} \\
(0.0061)\end{array}$ & & $\begin{array}{l}0.149^{* * *} \\
(0.0061)\end{array}$ & \\
\hline Composition effect & $\begin{array}{l}0.006^{* * *} \\
(0.0008)\end{array}$ & $4.0^{* * *}$ & $\begin{array}{c}0.004^{*} \\
(0.0021)\end{array}$ & $2.7^{*}$ & $\begin{array}{l}0.046^{* * *} \\
(0.0061)\end{array}$ & $30.9^{* * *}$ \\
\hline Wage effect & $\begin{array}{l}0.155^{* * *} \\
(0.0060)\end{array}$ & & $\begin{array}{l}0.145^{* * *} \\
(0.0063)\end{array}$ & & $\begin{array}{l}0.103^{* * *} \\
(0.0064)\end{array}$ & \\
\hline
\end{tabular}

Note: (a) The sample for all decompositions is 99,704 observations (54,505 women and 45,199 men). Bootstraped standard errors in parentheses, 300 repetitions. ${ }^{(* * *)},{ }^{(* *)}$, and ${ }^{(*)}$ denotes statistical significance at the 1,5 , and $10 \%$ levels, respectively. All three specifications include controls for type of university (public or private), year dummies, semester of graduation dummies, and dummy variables for the state where the university is located. In addition to these, specification (2) includes eight areas of study, and specification (3) includes 51 fields of study. The percentage of the gap explained is calculated as the compositions effect divided by the corresponding raw log wage gap. Weights for the decompositions are the same for the coefficients of men and women.

Source: Authors' calculations using social protection records and information from the Ministry of Education for 2007 and 2008 college graduates.

sitions in this table use equally weighted coefficients. First of all, Table 3 indicates that the gender wage gap varies with the level of wage, being larger at the top of the distribution than at the middle of it (the gap is smallest for low wages, reflecting the equalizing effect of the minimum wage in Colombia). Interestingly, there is a small, but statistically significant, gap of $1.6 \%$ at the 10 th percentile that increases to $11.8 \%$ at the median, and reaches $14.9 \%$ at the 90th percentile. This shows that very early in the career of these young professionals gender gaps are already present, and that phenomena like glass ceilings start to shape up. This is consistent with the results in Hoyos et al. (2007) for a more general sample of workers. 
From Table 3 it is also evident that controlling for subject of degree matters, although it matters the most when we include a detailed categorization of subject of degree (field of study in specification 3) than when we include a more aggregate measure (area of study in specification 2). For the median decomposition (panel B), for example, by including area of study we are able to explain $18.6 \%$ of the gender gap, while we explain $42.4 \%$ when we include field of study. We also find that the higher we go in the distribution of wages, the harder it is to explain the gender wage gap: when we we include area of study this figure decreases from $18.6 \%$ of the gap to a barely significant $2.7 \%$ (specification 2); similarly, including field of study (specification 3), while at the median we are able to explain $42.4 \%$ of the gap, at the 90th we only explain $30.9 \%$. This highlights the importance of using disaggregated measures of subject of degree that do not hide the substantial gender differences in pay observed in more aggregated measures.

\section{Conclusions}

Using unique, administrative datasets for recent college graduates in Colombia, this paper yields three results. First, from early on in their career, women earn lower wages compared to their male counterparts; this gap is on average 10.7\%. Second, gender differences in subject of degree explain at least $34 \%$, and up to $41 \%$ of the average wage gap. Finally, the gender gap for recent graduates exhibits glass ceiling effects, as women at the top of the distribution face higher wage gaps (12\% at the median and $15 \%$ at the top). A smaller proportion of the gap can be attributed to field of study at the top, $31 \%$, than at the middle of the distribution, $42 \%$. On average, thus, field of study explains 3-4\% higher wages for men relative to women.

In terms of policy implications, our findings suggest that policies to reduce the gender wage gap need to address the differing educational choices of men and women, and the cultural and economic factors driving these choices. On top of that, these policies will most likely have a larger impact on the gender wage gap for average- and median-wage workers than for top-wage workers, although for both these groups the potential effect is substantial. 


\section{References}

Albrecht, J., A. Bjorklund, and S. Vroman (2003, January). Is there a glass ceiling in Sweden? Journal of Labor Economics 21(1), 145-177.

Arulampalam, W., A. Booth, and M. Bryan (2007). Is there a glass ceiling over Europe? Exploring the gender wage gap across the wage distribution. Industrial and Labor Relations Review 60, 163-186.

Barón, J. D. and D. Cobb Clark (2010). Occupational segregation and the gender wage gap in private- and public- sector employment: A distributional analysis. Economic Record 86(273), $227-246$.

Blinder, A. S. (1973). Wage discrimination: Reduced form and structural estimates. The Journal of Human Resources 8, 436-455.

Chevalier, A. (2007). Motivation, expectations, and the gender pay gap for UK graduates. Oxford Bulletin of Economics and Statistics 69(6), 819-842.

Firpo, S., N. M. Fortin, and T. Lemieux (2009). Unconditional quantile regressions. Econometrica 77(3), 953-973.

Fortin, N., T. Lemieux, and S. Firpo (2011). Decomposition methods in economics. In O. Ashenfelter and D. Card (Eds.), Handbook of Economics, Volume IV.A, pp. 1-102. Amsterdam: North-Holland.

Hausmann, R., L. Tyson, and S. Zahidi (2011). The Global Gender Gap Report 2011. Geneva, Switzerland: World Economic Forum.

Hoyos, A., H. Nopo, and X. Pena (2007). The Persistent Earnings Gap in Colombia, 1994-2006. IDB Working Paper Series no. IDB-WP-174, Inter-American Development Bank, Washington DC, USA.

Lin, E. S. (2010). Gender wage gaps by college major in Taiwan: Empirical evidence from the 1997-2003 Manpower Utilization Survey. Economics of Education Review 29, 156-164.

Machin, S. and P. A. Puhani (2003). Subject of degree and the gender wage gap differential: Evidence from the UK and Germany. Economic Letters 79, 393-400.

McDonald, J. A. and R. J. Thornton (2007). Do new male and female college graduates receive unequal pay? Journal of Human Resources 42(1), 32-48.

Nopo, H. (2008). Matching as a tool to decompose wage gaps. Review of Economics and Statistics 90(2), 290-299.

Oaxaca, R. (1973). Male-female wage differentials in urban labor markets. International Economic Review 14, 693-709.

Reimers, C. W. (1983). Labor market discrimination against hispanic and black men. The Review of Economics and Statistics 65, 570-579. 


\section{Table A1: Subject of Degree (Field of Study) and Gender Wage Gaps ${ }^{(a)}$}

\begin{tabular}{|c|c|c|c|c|}
\hline Subject & $\begin{array}{c}\text { Female } \\
\text { graduates, \% }\end{array}$ & $\begin{array}{c}(2) \\
\text { Male } \\
\text { graduates, \% }\end{array}$ & $\begin{array}{c}(3) \\
\text { Average monthly } \\
\text { wage ('000) }\end{array}$ & $\begin{array}{c}(4) \\
\text { Wage ratio } \\
\left(w^{f} / w^{m}\right) \\
\end{array}$ \\
\hline Agronomy & 0.09 & 0.24 & 1,139 & 0.85 \\
\hline Zootechnics & 0.23 & 0.51 & 1,019 & 0.86 \\
\hline Veterinary medicine & 0.48 & 1.01 & 1,076 & 0.91 \\
\hline Visual \& plastic arts & 0.21 & 0.19 & 1,096 & 1.01 \\
\hline Advertising & 1.30 & 1.15 & 1,328 & 0.95 \\
\hline Design & 1.36 & 1.38 & 1,140 & 1.10 \\
\hline Music & 0.07 & 0.23 & 1,296 & 0.86 \\
\hline Business administration & 15.22 & 12.60 & 1,406 & 0.89 \\
\hline Education & 12.58 & 7.63 & 927 & 0.91 \\
\hline Bacteriology & 1.67 & 0.38 & 1,411 & 1.07 \\
\hline Nursing & 4.54 & 1.75 & 1,415 & 0.97 \\
\hline Therapy & 2.17 & 0.44 & 878 & 0.94 \\
\hline Surgical technology & 0.55 & 0.45 & 1,097 & 0.94 \\
\hline Medicine & 4.23 & 4.39 & 2,017 & 0.98 \\
\hline Nutrition & 0.44 & 0.09 & 1,235 & 1.09 \\
\hline Dentistry & 1.70 & 0.83 & 1,658 & 1.06 \\
\hline Optometry & 0.23 & 0.15 & 1,139 & 1.03 \\
\hline Anthropology \& liberal arts & 0.12 & 0.14 & 1,194 & 1.08 \\
\hline Library science & 0.11 & 0.11 & 1,616 & 0.98 \\
\hline Political science \& international relations & 0.36 & 0.32 & 1,361 & 1.02 \\
\hline Communications \& journalism & 2.59 & 1.78 & 1,230 & 1.03 \\
\hline Physical education & 0.15 & 0.44 & 910 & 0.97 \\
\hline Law & 6.85 & 6.98 & 1,645 & 0.92 \\
\hline Geography and history & 0.14 & 0.20 & 965 & 0.93 \\
\hline Literature, modern languages \& linguistics & 0.47 & 0.33 & 1,378 & 1.08 \\
\hline Psychology & 4.62 & 1.26 & 1,166 & 0.93 \\
\hline Philosophy and theology & 0.16 & 0.49 & 1,119 & 1.06 \\
\hline Sociology and social work & 2.01 & 0.47 & 1,067 & 0.92 \\
\hline Economics & 3.38 & 2.85 & 1,420 & 0.85 \\
\hline Public accounting & 10.89 & 6.53 & 1,238 & 0.85 \\
\hline Architecture & 0.87 & 1.80 & 1,133 & 1.08 \\
\hline Biomedical engineering & 0.18 & 0.19 & 1,348 & 0.83 \\
\hline Environmental and sanitary engineering & 1.32 & 1.26 & 1,256 & 0.91 \\
\hline Business engineering & 1.03 & 0.70 & 1,573 & 0.87 \\
\hline Agricultural \& forestry engineering & 0.18 & 0.31 & 1,244 & 1.02 \\
\hline Agro-industrial \& food engineering & 0.73 & 0.83 & 1,066 & 0.97 \\
\hline Agronomy \& livestock engineering & 0.38 & 1.09 & 1,181 & 0.87 \\
\hline Civil engineering & 1.47 & 4.44 & 1,457 & 1.01 \\
\hline Mining \& metallurgical engineering & 0.50 & 1.39 & 2,564 & 1.00 \\
\hline Systems engineering & 3.69 & 8.89 & 1,469 & 0.88 \\
\hline Electrical engineering & 0.29 & 1.78 & 1,543 & 1.10 \\
\hline Electronic engineering \& telecommunications & 1.32 & 6.37 & 1,521 & 0.97 \\
\hline Industrial engineering & 5.19 & 7.36 & 1,568 & 0.90 \\
\hline Mechanical engineering & 0.40 & 4.30 & 1,582 & 0.97 \\
\hline Chemical engineering & 1.01 & 1.19 & 1,507 & 0.86 \\
\hline Other engineering & 0.13 & 0.20 & 1,140 & 1.03 \\
\hline Biology \& microbioloby & 1.08 & 0.73 & 1,100 & 1.05 \\
\hline Physics & 0.07 & 0.27 & 1,051 & 1.28 \\
\hline Geology \& other programs in the natural sciences & 0.15 & 0.24 & 2,658 & 0.85 \\
\hline Mathematics \& statistics & 0.17 & 0.46 & 1,433 & 0.89 \\
\hline Chemistry & 0.91 & 0.87 & 1,529 & 0.99 \\
\hline Total & 100.0 & 100.0 & 1,377 & 0.88 \\
\hline
\end{tabular}

Note: (a) The total sample used is 99,704 (54,505 women and 45,199 men). The sample includes only college graduates with a formal job. In column $(4), w^{(f)}$ corresponds to average female wages and $w^{(m)}$ to average male wages. Source: Authors' calculations using social protection records and information from the Ministry of Education for 2007 and 2008 college graduates. 